Jonathan P. Purday MB BS MRCP(UK) FRCA, Clayton C. Reichert MD FRCPC, Pamela M. Merrick BSN

\title{
Comparative effects of three doses of intra- venous ketorolac or morphine on emesis and analgesia for restorative dental surgery in children
}

Purpose: The optimal dose of intravenous ketorolac tromethamine (ketorolac), a non-steroidal anti-inflammatory drug has not been determined in children. There are only limited published data on the use of intravenous ketorolac for paediatric analgesia. This study compares the analgesic and emetic effect of three different doses of ketorolac with morphine in paediatric dental surgical out-patients.

Methods: Following institutional approval and parental consent, 120 ASA I or II children, age 2-10 yr were randomized to four groups and received ketorolac $0.75,1.0$, and 1.5 $\mathrm{mg} \cdot \mathrm{kg}^{-1}$ or morphine $0.1 \mathrm{mg} \cdot \mathrm{kg}^{-1}$ iv at induction of a standardized anaesthetic. At 15 and $30 \mathrm{~min}$ after arrival in the recovery room a blinded observer assessed pain using the Objective Pain Score (OPS). Twenty-four hours after surgery a telephone interview was carried out with a parent at home. Results: There were no differences in demographic data, anaesthesia time, recovery and day-care unit time, OPS and postoperative analgesic requirements in the four groups. Postoperative vomiting in the first $24 \mathrm{hr}$ occurred more frequently in the morphine group than in the other groups $(P<$ 0.0166). No patient had excessive surgical bleeding.

\section{Key words}

ANAESTHESIA: paediatric;

ANALGESICS: ketorolac, morphine;

COMPLICATIONS: postoperative vomiting;

PAIN: postoperative.

From the Departments of Anaesthesia, University of British

Columbia and British Columbia Children's Hospital,

Vancouver, British Columbia, Canada.

Address correspondence to: Dr. Jonathan Purday, Anaesthetics Department, Frenchay Hospital, Bristol BS16 1LE, United Kingdom.

Accepted for publication 25th October, 1995.
Conclusions: Ketorolac, in all doses studied $(0.75,1.0$ and 1.5 $\mathrm{mg} \cdot \mathrm{kg}^{-1}$ ) was as effective an analgesic as morphine 0.1 $\mathrm{mg} \cdot \mathrm{kg}^{-1}$ given intravenously at induction to children having restorative dental surgery. Its use was associated with a significant reduction in the incidence of postoperative vomiting.

Objectif: La dose intraveineuse optimale de kétorolac trométhamine (kétorolac), un anti-inflammatoire non stérö̈dien n'a pas encore été déterminée chez l'enfant. Il existe peu de publications sur l'utilisation du kétorolac intraveineux en pédiatrie. Cette étude compare l'effet analgésique et émétique de trois doses différentes de kétorolac avec celui de la morphine en chirurgie dentaire pédiatrique ambulatoire.

Méthode: Avec l'approbation de l'institution et le consentement des parents, 120 jeunes patients ASA I et II, âgés de 2 à 10 ans ont été aléatoirement répartis en quatre groupes et ont reçu du kétorolac $0,75,1,0$ et $1,5 \mathrm{mg} \cdot \mathrm{kg}^{-1}$ ou de la morphine $0,1 \mathrm{mg} \cdot \mathrm{kg}^{-1}$ iv à l'induction d'une anesthésie standardisée. Après 15 et 30 min de l'admission en salle de réveil, un observateur neutre a évalué la douleur grâce à un score de douleur objective.

Résultats: Il n'y a pas eu de différences quant aux données démographiques, à la durée de l'anesthésie, au séjour en salle de réveil et au service de chirurgie d'un jour, aux scores de douleur et aux besoins d'analgésiques entre les quatres groupes. Pendant les 24 h postopératoires initiales, des vomissements sont survenus plus fréquemment dans le groupe morphine que dans les autres groupes $(P<0,0166)$. Aucun des patients n'a saigné de façon exagérée.

Conclusion: Lorsqu'administré par la voie intraveineuse à l'induction, le kétorolac, à toutes les doses utilisées $(0,75,1,0$ et $1,5 \mathrm{mg} \cdot \mathrm{kg}^{-1}$ ) est un analgésique aussi efficace que la morphine $1 \mathrm{mg} \cdot \mathrm{kg}^{-1} \mathrm{chez}$ des enfants soumis à une chirurgie dentaire reconstituante. Son utilisation s'est accompagnée d'une réduction importante de l'incidence des vomissements postopératoires. 
The optimal dose of intravenous ketorolac tromethamine, a non-steroidal anti-inflammatory drug (NSAID) has yet to be defined in children. This is despite the fact that NSAIDs are being used more frequently in the perioperative setting., 1,2 There are few trials using intravenous ketorolac after paediatric surgery and experience of its safety during the perioperative period are lacking, particularly in children. ${ }^{3-5}$ Most studies in children have given ketorolac $0.9 \mathrm{mg} \cdot \mathrm{kg}^{-1}$, but pharmacokinetic studies suggest a dose range of $0.8-1.5 \mathrm{mg} \cdot \mathrm{kg}^{-1}{ }^{-1,7}$ The expense of ketorolac has been the subject of recent controversy ${ }^{8,9}$ and, if lower doses are as effective, there may be considerable cost savings. In addition, in Europe, the initial adult dose of ketorolac has been reduced from 30 $\mathrm{mg}$ to $10 \mathrm{mg}$ amid fears of the drug being linked with fatalities from gastrointestinal haemorrhage, particularly in elderly patients who had repeated doses.. 10,11 However, there is no evidence of serious side effects in children.

Ketorolac and other NSAIDs have been suggested as an alternative to parenteral opioids to decrease the incidence of postoperative vomiting ${ }^{12}$ and would seem to be particularly helpful for day case anaesthesia. Intraoperative ketorolac $0.9 \mathrm{mg} \cdot \mathrm{kg}^{-1}$ iv was as efficacious as morphine $0.1 \mathrm{mg} \cdot \mathrm{kg}^{-1}$ iv for postoperative analgesia and reduced emesis. ${ }^{3}$ This randomized, double-blind, prospective study was designed to assess the analgesic effects of three different doses of ketorolac $(0.75,1.0$ and $\left.1.5 \mathrm{mg} \cdot \mathrm{kg}^{-1}\right)$, predicted from pharmacokinetic studies, ${ }^{6,7}$ compared with that of morphine $\left(0.1 \mathrm{mg} \cdot \mathrm{kg}^{-1}\right)$ for control of pain following day case dental restorative surgery.

\section{Methods}

Following institutional approval from British Columbia's Children's Hospital and the University of British Columbia and written informed parental consent, 120 ASA I or II children, aged $2-10 \mathrm{yr}$ were studied. Children presenting for day-care dental restorative surgery were examined as their surgery, often involving extractions and pulpotomies, was known to be associated with moderate-to-severe pain and parenteral opioids were routinely administered. We excluded patients with cardiovascular disease, asthma, renal dysfunction, peptic ulceration, bleeding disorders, and mental retardation.

Patients were randomized to four groups to receive ketorolac $0.75,1.0$, and $1.5 \mathrm{mg} \cdot \mathrm{kg}^{-1}$ or morphine 0.1 $\mathrm{mg} \cdot \mathrm{kg}^{-1}$ iv in a standardized manner at induction of anaesthesia. Patients were unpremedicated and routine monitoring was attached. After intravenous access was established, anaesthesia was induced intravenously with propofol $5 \mathrm{mg} \cdot \mathrm{kg}^{-1}$, lidocaine $1 \mathrm{mg} \cdot \mathrm{kg}^{-1}$, atropine 20 $\mu \mathrm{g} \cdot \mathrm{kg}^{-1}$ and succinylcholine $2 \mathrm{mg} \cdot \mathrm{kg}^{-1}$ with subsequent nasotracheal intubation of the trachea. Two pharyngeal throat packs were positioned to absorb any intraoperative blood loss. Anaesthesia was continued with $0.5-1.5 \%$ halothane in $66 \%$ nitrous oxide in oxygen, titrated to avoid signs of light anaesthesia (lacrimation, increasing heart rate, respiratory rate and blood pressure).

The exact nature of the surgery performed was recorded. At the end of surgery the halothane was discontinued and the child's trachea extubated, once spontaneous eye opening had occurred. The total anaesthesia time and time from discontinuation of anaesthesia to tracheal extubation were noted.

At 15 and $30 \mathrm{~min}$. after arrival in the recovery room a blinded observer assessed pain using the previously validated Objective Pain Score (OPS). ${ }^{13}$ Oral acetaminophen $\left(20 \mathrm{mg} \cdot \mathrm{kg}^{-1}\right)$ or codeine $\left(1 \mathrm{mg} \cdot \mathrm{kg}^{-1}\right)$ was given for pain when OPS $>6$. Assessments of sedation and side effects were also recorded. Sedation was assessed according to a graded sedation scale: $0=$ fully awake; 1 = slightly drowsy; 2 = asleep, easily roused; 3 $=$ asleep, difficult to rouse; $4=$ not rousable.

Total time in the post-anaesthetic care unit (PACU) or day-care unit (DCU) was also recorded.

The following day the total amount of acetaminophen given, the incidence of vomiting and bleeding and other side effects were determined by telephone interview.

Age, weight, duration of anaesthesia, time to extubation, time in PACU, and time in DCU and OPS for the four groups were assessed for normality of distribution using the Martinez-Iglewicz, the Kolmogorov-Smirnov, and the D'Agostino-Pearson Omnibus $\mathrm{K}^{2}$ normality tests and analyzed for between group differences using the Kruskal-Wallis test (NCSS computer program, version 5.03). Data were expressed as medians and ranges (skewed), or as counts and percentages (categorical). Chi-square and Fisher's exact test were used to compare the four groups on ASA physical status, sex, extractions, pulpotomies, the number of patients who vomited postoperatively, and the number of patients who received acetaminophen at home. Sedation scores and number of doses of analgesics had to be reduced to yes/no counts and analyzed with Chi-square or Fisher's exact tests due to their non-continuous distributions. A probability $(P)$ value of less than 0.05 was considered significant, except where Bonferroni's correction was used for multiple intergroup comparisons in contingency tables. Sample size was chosen to identify a reduction of mean visual analogue score (VAS) from 2 to 1 , which was felt to be clinically important. Pre-study power calculations, based on a previously published study, ${ }^{3}$ determined that we needed 28 patients per group to find a $50 \%$ differ- 
TABLE I Demographic data and emergence times

\begin{tabular}{lllll}
\hline & $\begin{array}{l}\text { Ketorolac } \\
0.75 \mathrm{mg} \cdot \mathrm{kg}^{-1}\end{array}$ & $\begin{array}{l}\text { Ketorolac } \\
1.0 \mathrm{mg} \cdot \mathrm{kg}^{-1}\end{array}$ & $\begin{array}{l}\text { Ketorolac } \\
1.5 \mathrm{mg} \cdot \mathrm{kg}^{-1}\end{array}$ & $\begin{array}{l}\text { Morphine } \\
0.1 \mathrm{mg} \cdot \mathrm{kg}^{-1}\end{array}$ \\
\hline Number (n) & 30 & 30 & 30 & 30 \\
Age (yr) & $4(2-10)$ & $4(2-8)$ & $4(3-9)$ & $4(2-8)$ \\
Weight (kg) & $16(13-42)$ & $16(12-29)$ & $17(11-26)$ & $17(13-30)$ \\
Sex (M/F) & $12 / 18$ & $13 / 17$ & $14 / 16$ & $14 / 16$ \\
ASA (I/II) & $26 / 4$ & $28 / 2$ & $28 / 2$ & $27 / 3$ \\
Extractions & $12(40 \%)$ & $13(43 \%)$ & $16(53 \%)$ & $13(43 \%)$ \\
Pulpotomies & $7(23 \%)$ & $17(57 \%)$ & $12(40 \%)$ & $11(37 \%)$ \\
Restorations & 30 & 30 & 30 & 30 \\
Anaesthesia time (min) & $82(30-147)$ & $84(35-195)$ & $92(35-162)$ & $101(25-155)$ \\
Extubation time (min) & $5(1-17)$ & $5(1-15)$ & $4(2-12)$ & $6(1-17)$ \\
Recovery time (min) & $43(19-78)$ & $52(29-80)$ & $44(30-87)$ & $47(30-100)$ \\
Day Care Unit time (min) & $79(34-158)$ & $76(38-123)$ & $75(50-102)$ & $83(45-132)$ \\
\hline
\end{tabular}

Data are expressed as medians and ranges or counts and percentages.

TABLE II Objective pain and sedation scores at 15 and $30 \mathrm{~min}$ and comparison of analgesic therapy and emesis in the postoperative period.

\begin{tabular}{lccccc}
\hline & $\begin{array}{c}\text { Ketorolac } \\
0.75 \mathrm{mg} \cdot \mathrm{kg}^{-1}\end{array}$ & $\begin{array}{l}\text { Ketorolac } \\
1.0 \mathrm{mg} \cdot \mathrm{kg}^{-1}\end{array}$ & $\begin{array}{l}\text { Ketorolac } \\
1.5 \mathrm{mg} \cdot \mathrm{kg}^{-1}\end{array}$ & $\begin{array}{l}\text { Morphine } \\
0.1 \mathrm{mg}^{-1} \mathrm{~kg}^{-1}\end{array}$ & $P$ \\
\hline OPS 15 min* & $1(0-10)$ & $2(0-6)$ & $2(0-8)$ & $0(0-7)$ & 0.27 \\
OPS 30 min* & $0(0-6)$ & $1(0-7)$ & $1(0-6)$ & $1(0-7)$ & 0.27 \\
Acetaminophen $(\mathrm{H}) \dagger$ & $12(40 \%)$ & $14(47 \%)$ & $12(40 \%)$ & $7(23 \%)$ & 0.44 \\
Codeine: $(\mathrm{H}) \dagger$ & $5(17 \%)$ & $3(10 \%)$ & $5(17 \%)$ & $2(7 \%)$ & 0.56 \\
Sedation score 15 min $\dagger$ & $20(67 \%)$ & $17(15 \%) \ddagger$ & $16(53 \%) \ddagger$ & $26(87 \%)$ & 0.03 \\
Sedation score 30 min $\dagger$ & $4(13 \%)$ & $7(23 \%)$ & $4(13 \%)$ & $10(33 \%)$ & 0.17 \\
Vomited $\dagger$ & $6(20 \%) \ddagger$ & $5(17 \%) \ddagger$ & $1(3 \%) \ddagger$ & $16(53 \%)$ & 0.00 \\
Analgesics at home $\dagger$ & $10(33 \%)$ & $15(50 \%)$ & $14(47 \%)$ & $7(23 \%)$ & 0.12 \\
\hline
\end{tabular}

Data are expressed as medians and ranges or counts and percentages.

*Median (range).

†Yes (\%)

$\ddagger P<0.0166$.

$(\mathrm{H})=$ hospital.

ence in VAS scores assuming a mean or median of 2 in the control group and a mean of 1 in any treatment group, and a SD of 1.3. These calculations assumed that VAS scores would be used to measure pain and that the distributions of scores would be normal.

\section{Results}

There were no differences among the groups in ages, weight, type of surgery performed, duration of anaesthesia, time to extubation, time in PAR, and time in DCU (Table I). These results were not normally distributed as tested by the normality testing.

No differences could be detected in the OPS at 15 or 30 min between the morphine and ketorolac groups (Table II). Again, these results were not normally distributed. In addition, there were no differences in postoperative analgesic requirements in the four groups for acetaminophen or codeine within the hospital $(27-47 \%)$.
At $15 \mathrm{~min}$, the morphine group had greater sedation than ketorolac 1.0 or $1.5 \mathrm{mg} \cdot \mathrm{kg}^{-1}$ but not at the 0.75 $\mathrm{mg} \cdot \mathrm{kg}^{-1}$ dose. Postoperative vomiting occurred more frequently in the morphine group than all the ketorolac groups in the first $24 \mathrm{hr}$ after discharge $(P<0.0166)$. No differences could be detected in the need for acetaminophen in the first $24 \mathrm{hr}$ after discharge (23-50\%). No patient had excessive surgical bleeding.

\section{Discussion}

Non-steroidal anti-inflammatory drugs (NSAIDs) are currently featured prominently in the literature of postoperative pain management and have been promoted for use as part of a balanced analgesic regimen with opioids and local anaesthetics. ${ }^{14,15}$ These agents seem ideal for day-case surgery where the lack of the opioid side effects of sedation, respiratory depression and nausea, may lead to more rapid discharge of patients. Ketorolac 
has been promoted as an NSAID with potent analgesic properties $^{16}$ and was the first injectable NSAID to be given FDA approval and has subsequently been the subject of recent drug trials. However, the dose of ketorolac that should be used postoperatively in adults is currently under review. ${ }^{10,11}$ The dose to be used in children is even more uncertain. Only $0.9 \mathrm{mg} \cdot \mathrm{kg}^{-1}$ and 0.75 $\mathrm{mg} \cdot \mathrm{kg}^{-1}$, to a lesser extent, have previously been studied. $^{2-4}$ Despite Hannullah's plea in $1992^{1}$ there have been few randomized double-blind studies since. ${ }^{4}$

Our study can be criticized for its sample size, even though 120 patients were studied. Pre-study power calculations based on previously published results determined that we needed 28 patients per group using VAS, not OPS, to ensure a power of $80 \%$. Unfortunately, many of the children were too young to score VAS reliably and, therefore, only OPS could be used, which turned out to have very skewed distributions and very different values from what others had found. Therefore, the power for our outcome variable ended up as being lower than we expected (40\%, to find a $50 \%$ difference between groups in OPS scores). This criticism can be leveled at the other published studies using an OPS sys$t^{t e m^{3-5}}$ and is a common fault among published negative clinical studies. ${ }^{19,20}$ To our knowledge this is the largest prospective study comparing intravenous ketorolac with morphine in children and in the 90 patients given ketorolac no differences could be detected in its use compared with morphine $0.1 \mathrm{mg} \cdot \mathrm{kg}^{-1}$ to control the pain of dental restorative surgery. There is a need for larger prospective, double-blind, multi-centre studies for conclusive proof that ketorolac has similar efficacy to morphine for analgesia in young children. Perhaps, in the future, it may be possible to perform a meta-analysis of all the studies of intravenous ketorolac.

The effects of ketorolac in reducing postoperative vomiting in the first twenty-four hours was significant $(P<0.0166)$ in all doses compared to morphine. The true incidence of postoperative nausea and vomiting in the paediatric population is difficult to determine accurately and, in younger infants, nausea can be impossible to define. An analysis of pooled data gives an incidence between $20-35 \%$ for the age group of our patients. ${ }^{21}$ The study's incidence of 53\% for the morphine group compares with that after squint surgery ${ }^{21}$ and is most likely due to a combination of an opioid and swallowed blood. The impressively low incidence of vomiting of $3 \%$ in the ketorolac $1.5 \mathrm{mg} \cdot \mathrm{kg}^{-1}$ group did not reach statistical significance with respect to the other ketorolac groups but may indicate that differing doses may have additional effects.

As has been stated by a recent editorial, the costeffectiveness of a new treatment has, in the present environment, become increasingly important. ${ }^{22}$ Ketorolac is more expensive than morphine, but the additional cost of anti-emesis treatment must be included in calculating the cost-benefit ratio to the patient. ${ }^{23}$

The effect of ketorolac on perioperative bleeding is controversial. It would be expected that, like other NSAIDs, ketorolac would affect the production of thromboxane- $\mathrm{A}_{2}$ and subsequently platelet function. Thromboelastography as a marker of platelet function has been unaffected in a recent study in 86 children three hours after $0.75 \mathrm{mg} \cdot \mathrm{kg}^{-1}$ given intramuscularly. ${ }^{24}$ There have been isolated case reports linking ketorolac to increased perioperative haemorrhage. ${ }^{10,25,26}$ In our study, however, no clinical increase in bleeding complications could be detected despite giving the drug on induction and not postoperatively as has been suggested by some authors. ${ }^{15}$

In conclusion, therefore, $0.75,1.0$ and $1.5 \mathrm{mg} \cdot \mathrm{kg}^{-1}$ seem equally effective as morphine $0.1 \mathrm{mg} \cdot \mathrm{kg}^{-1}$ in controlling pain after dental restorative surgery in young children and are far less likely to cause vomiting. The reduction in adult doses ${ }^{10,11}$ may indicate that, in children, even lower doses of $0.3-0.5 \mathrm{mg} \cdot \mathrm{kg}^{-1}$ may be equally effective. Further large, carefully controlled studies are needed, perhaps comparing even lower doses and examining efficacy and cost-effectiveness, before any firm recommendations can be made of the paediatric dosage of ketorolac tromethamine.

\section{Acknowledgements}

The staff of the post anaesthetic care unit and dental operating rooms of the British Columbia's Children's Hospital, Vancouver for their assistance during this study.

\section{References}

1 Hannallah $R S$. Postoperative analgesia in the paediatric patient (Editorial). Can J Anaesth 1992; 39: 641-2.

2 Dahl JB, Kehlet $H$. Non-steroidal anti-inflammatory drugs: rationale for use in severe postoperative pain. $\mathrm{Br} \mathrm{J}$ Anaesth 1991; 66: 703-12.

3 Watcha MF, Jones MB, Lagueruela RG, Schweiger CS, White $P F$. Comparison of ketorolac and morphine as adjuvants during pediatric surgery. Anesthesiology 1992; 76: 368-72.

4 Desparmet JF, MacArthur C, MacArthur A, Grillas B. Pain and vomiting after tonsillectomy in children: a comparison of intra-operative ketorolac and fentanyl. Anesthesiology 1993; 79: A1194.

5 Munro HM, Riegger LQ, Reynolds PI, Wilton NCT, Lewis $I H$. Comparison of the analgesic and emetic properties of ketorolac and morphine for paediatric outpatient strabismus surgery. Br J Anaesth 1994; 72: 624-8. 
6 Olkkola KT, Maunuksela E-L. The pharmacokinetics of postoperative intravenous ketorolac tromethamine in children. Br J Clin Pharmacol 1991; 31: 182-4.

7 Cohen DE, Siegal S, Davis L, Kurth CD, Schreiner MS. Pharmacokinetics of intravenous ketorolac in infants less than 1 year of age. Anesthesiology 1994; 81: A1334.

8 Ariano RE, Zelenitsky SA. Ketorolac (Toradol): a marketing phenomenon (Editorial). Can Med Assoc J 1993; 148: 1686-8.

9 Spickler W. Ketorolac (Toradol): a new analgesic or an old NSAID? (Editorial) Can Med Assoc J 1993; 148: 1693-5.

10 Committee on Safety of Medicines. Ketorolac: new restrictions on dose and duration of treatment. Current Problems in Pharmacovigilance 1993; 19: 5-6.

11 Choo V, Lewis $S$. Ketorolac doses reduced (Letter). Lancet 1993; 342: 109

12 Watcha $M F$, White $P F$. Postoperative nausea and vomiting. Its etiology, treatment, and prevention. Anesthesiology 1992; 77: 162-84.

13 Broadman LM, Rice LJ, Hannallah RS. Testing the validity of an objective pain scale for infants and children. Anesthesiology 1988; 69: A770.

14 Norden J, Hannallah R, Getson P, O'Donnell R, Kelliher $G$, Walker $N$. Concurrent validation of an objective pain scale for infants and children. Anesthesiology 1991; 75: A934.

15 Murphy $D F$. NSAIDs and postoperative pain (Editorial). BMJ 1993; 306: 1493-4.

16 Kehlet $H$. Postoperative pain relief - what is the issue? (Editorial). Br J Anaesth 1994; 72: 375-8.

17 Kenny GNC. Ketorolac trometamol - a new non-opioid analgesic. Br J Anaesth 1990; 65: 445-7.

18 Watcha $M F$, Ramirez-Ruiz $M$, White PF, Jones $M B$, Lagueruela RG, Terkonda RP. Perioperative effects of oral ketorolac and acetaminophen in children undergoing bilateral myringotomy. Can J Anaesth 1992; 39: 649-54.

19 Freiman JA, Chalmers TC, Smith H Jr, Kuebler RR. The importance of beta, the type II error and sample size in the design and interpretation of the randomized control trial. Survey of 71 "negative" trials. N Eng J Med 1978; 299 : 690-4.

20 Altman DG. Statistics and ethics in medical research. III How large a sample? BMJ 1980; 281: 1336-9.

21 Lerman J. Surgical and patient factors involved in postoperative nausea and vomiting. Br J Anaesth 1992; 69 : 24S-32S.

22 White $P F$, Watcha $M F$. Are new drugs cost-effective for patients undergoing ambulatory surgery? (Editorial). Anesthesiology 1993; 78: 2-5.

23 Lippmann M, Ginsburg R. Increased cost of ketorolac versus morphine sulfate (Letter). Anesthesiology 1992; 77 : 601.

24 Bean JD, Hunt R, Custer MD. Effects of ketorolac on postoperative analgesia and bleeding time in children. Anesthesiology 1993; 79: A1190.

25 Fleming BM, Coombs $D W$. Bleeding diathesis after perioperative ketorolac (Letter). Anesth Analg 1991; 73: 235.

26 Read JRM, Bainton R. Operative haemorrhage in association with ketorolac (Letter). Anaesthesia 1994; 49: 73-4. 